\begin{tabular}{|c|}
\hline $\begin{array}{c}\text { Asian Social Work Journal (ASWJ) } \\
\text { ASIAN SOCIAL WORK } \\
\text { JOURAL } \\
\text { (ASW) }\end{array}$ \\
Volume 1, Issue 1, May 2016 \\
Journal home page: \\
www.msocialwork.com \\
\hline
\end{tabular}

\title{
Improving The Health Related Quality of Life of Children with Autism
}

\author{
Amelia Inbam Neelagandan ${ }^{1}$, Mohd Dahlan Hj A Malek ${ }^{2}$ \\ ${ }^{1}$ Queen Elizabeth Hospital Kota Kinabalu, Sabah \\ 2Universiti Malaysia Sabah
}

Correspondence: Amelia Inbam Neelagandan (amelia.inbam@gmail.com)

\begin{abstract}
This is a conceptual paper that investigates how the health related quality of life (HRQOL) of children with autism can be improved. The paper involves a literature review of background information regarding autism, studies documenting the HRQOL of children with autism and factors affecting the HRQOL of children with autism. The aim of this study is to propose an intervention procedure that will help to improve the HRQOL of children with autism. The intervention was developed based on autism clinical practice guidelines and best practice recommendations. Literature shows that HRQOL among children with autism is lower than the general population. Based on the impairment among children with autism, the factors that affect the HRQOL and best practice guidelines for autism intervention, this paper concludes that an ideal intervention program to improve the HRQOL of children with autism would be a parent training program or parent mediated intervention (PMI) that includes strategies to manage challenging behavior, adaptive skills, and social communication skills.
\end{abstract}

Key words: autism spectrum disorder, parent training, health related quality of life (HRQOL), social communication, autism intervention, parent mediated intervention

\section{Introduction}

Autism is a pervasive developmental disorder (Volkmar, Rogers, Paul, and Pelphrey, 2014). It affects many areas of a child's life, from the fundamentals of childhood such as play and learning, to the core of life, such as socializing, and understanding others and being understood. In some cases, it affects behavior, attention, and results in a multitude of socially unacceptable characteristics. (Lai, Lombardo, \& Baron-Cohen, 2014)

Due to poor language and social skills, (Lombardo, Pierce, Eyler, Barnes, Ahrens-Barbeau, Solso, Campbell, and Courchesne, 2015; Magiati, Tay, and Howlin, 2014) individuals with autism have very few meaningful relationships, and often lack any form of social interaction beyond their immediate family (Calder, L., Hill, V. and Pellicano, E., 2013; Laugeson, Gantman, Kapp, Orenski, and Ellingsen, 2015). As social and community involvement and interaction forms a part of HRQoL, this contributes to low QoL among this population (Olsson, Tammimies, and Bölte, 2015).

Every aspect of life involves communication and socially acceptable behaviour, including sports and physical activity. Although not directly related, studies have shown that even the physical domain of HRQoL is lower among children with autism compared to the general population (Tung, L.C., Huang, C.Y., Tseng, M.H., Yen, H.C., Tsai, Y.P., Lin, Y.C. and Chen, K.L., 2014). 
In addition to the impact on the child with autism, evidence suggest an equally negative impact and burden on parents, caregivers and families caring for a child with autism. Parents, especially mothers, have reported increased stress levels and increased depression compared to parents of typically developing children. (Montes, G., \& Halterman, J. S., 2007)

There are numerous intervention programs currently available for children with autism, however, none of it explicitly targets an improvement in HRQOL as an outcome measure. Due to the severity of autism and the far reaching impact it has on children and families; a suitable intervention program needs to be developed in order to improve the HRQOL of children with autism.

\section{Purpose of Inquiry \& Inquiry Questions}

The HRQOL among children with autism is documented to be lower than children in the general population. This finding prompted the need to work on improving the HRQOL of children with autism. The main aim of this conceptual paper is to propose an intervention that will be able to improve the HRQOL of children with autism. In order to develop an appropriate intervention program, a few questions needed to be explored. The questions were:

1) What are the factors influencing the HRQOL among children with autism? This is important as the proposed intervention needs to target the areas that are influencing the HRQOL in order to improve it.

2) What are best practice recommendations for autism intervention? While the proposed intervention will focus on improving HRQOL, it will need to be designed in line with best practice guidelines for autism intervention.

The above questions will be investigated through a review of literature in the fields of autism and HRQOL as well as Clinical Practice Guidelines and other documents that guide and recommend intervention in the field of autism.

The inquiry questions are relevant as this paper intends to propose an intervention that will be able to provide a feasible solution to the problem of low HRQOL among children with autism. This paper is significant as it aims to propose an intervention with a clear outcome measure, which is improved HRQOL. This conceptual paper is timely and important as the prevalence of autism is on the rise and there is an urgency for an intervention program that is effective and accessible to families.

\section{Autism}

Autism is a neurodevelopmental disorder, characterized by difficulty in social communication, restricted and repetitive behavior and narrow interests (APA, DSM 5, 2013). Individuals with autism also demonstrate atypical language development, inconsistent or atypical language abilities, motor abnormalities and often excessive attention to detail (Lai, Lombardo, \& Baron-Cohen, 2014).

The prevalence of ASD in Malaysia is approximately 1.6 in 1,000. (Family Health Division. Ministry of Health Malaysia, 2006). In the USA, the overall prevalence of ASD is 14.7 per 1,000 (one in 68) children aged 8 years old. (Developmental Disabilities Monitoring Network Surveillance Year 2010 Principal Investigators; Centers for Disease Control and Prevention, CDC 2014). The prevalence of ASD has increased markedly over the past two decades, rising from 2 per 10,000 in 1990 to between 1 in 50 and 1 in 88 children (Blumberg, et al., 2013; Centers for Disease Control and Prevention, 2012)

The actual number of children with autism may vary, due to the different diagnostic criteria and referral policies at various healthcare centres. 
The impact of autism on the affected child is poor relationships and school performance, often leading to other behavior issues. There is also a substantial impact on families, with increased stress and financial and parenting burdens (Karst \& Van Hecke, 2012; Kogan, Strickland, Blumberg, Singh, Perrin, \& van Dyck, 2008)

Autism has serious and far reaching effects on the affected child, his family and the community at large. An intervention that will be able to help improve the HRQOL of children with autism has the potential to also improve the family quality of life and the healthcare system.

\section{HRQOL among Children with Autism}

Quality of Life is how happy or satisfied a person is with the various aspects of their life which is important to them (Oleson, 1990) This can include various domains or areas that affect an individual, such as their physical \& material well-being, relationship with others, social $\&$ community activities, personal development and recreation (Flanagan, 1978). Quality of life is an important concept, and a good quality of life is a desired state for a healthy population, and an expected outcome for medical intervention.

To specifically gauge the quality of life in the area of health and the outcome of treatment, a new concept called the Health Related Quality of Life was coined. Health-related quality of life (HRQOL) is the perception of the impact an illness/injury, medical treatment and/or health care policy has on one's life (Spieth LE, Harris CV, 1996). HRQOL, although specifically measuring health issues, is still multidimensional and includes physical, emotional, and social functioning. (Varni, Burwinkle, Seid, Skarr 2003). Where Quality of Life is broad and general in nature, covering a wide range of a person's life, HRQOL is more focused, and deals mainly with factors that are related to their health, interventions, health care providers \& the health care system they are in (Wilson \& Cleary, 1995)

The HRQOL in healthy populations is generally reported to be high, (Carter, Shaw, Collings, Blakely, Richardson, 2011, Norman, Church, van den Berg, Goodall, 2013). However, individuals with health issues, illnesses and disabilities have reported lower HRQOL compared to the general population (Simon, Kevin, Espiea, 2010; Petersson, Huus, Samuelsson, Hanberger, Akesson, 2015)

Lower HRQOL was not only reported among adults but also by children and adolescents with chronic medical and psychiatric conditions (Varni, Limbers, Burwinkle, Tasha, 2007) and various disabilities such as cerebral palsy (Rosenbaum, Livingston, Palisano, Galuppi, Russell, 2007; Dobhal, Juneja, Jain, Sairam, Thiagarajan, 2007), specific language impairment (Arkkila, Räsänen, Roine, Sintonen, Saar, Vilkman, 2011, Nicola, \& Watter, 2015), ADHD (Wehmeier, Schacht, Escobar, Hervas, Dickson, 2012,) and autism (Kuhlthau, Orlich, Hall, Sikora, Kovacs, Delahaye, Clemons, 2012; Kose, Erermis, Ozturk, Ozbaran, Demiral, Bildik, Tezan Aydin, Cahide, 2013). Kuhlthau et al (2012) also found that children with autism demonstrated lower HRQOL compared to children with chronic medical conditions.

The lower HRQOL among children autism spectrum disorder (ASD) may be explained by the pervasive nature of the disorder. Children affected by autism have difficulties in social communication, social interaction; and restricted and repetitive behaviour, interests, or activities (APA, DSM - 5, 2013). Autism affects about $1 \%$ of the world population (CDC, 2014). Social communication and interaction are among the core difficulties for children with autism, leading to poor interaction with others, and limited social activities. Behavior issues have also been shown to affect the HRQOL of children with ASD (Kuhlthau et al.2013)

While HRQOL among individuals with autism and their caregivers have been studied and documented to be low, there is little evidence in terms of intervention programs that aim to improve the HRQOL among this population. It is also the responsibility of professionals in the field of autism intervention to "disseminate top quality autism treatment and increase access to evidence-based treatment to ensure 
that individuals with ASD have the opportunity to fulfill their potential and lives that are as independent as possible" (Granpeesheh \& Tarbox, 2014)

\section{Factors affecting the HRQOL among Children with Autism}

There are many possible factors that influence the HRQOL of children with autism. Autism severity seems to be an obvious factor. Children who had a more severe diagnosis of autism had lower HRQOL compared to children with a milder version. (Kose, Erermis, Ozturk, Ozbaran, Demiral, Bildik, et al. 2013 \& Tilford, Payakachat, Kovacs, Pyne, Brouwer, Nick et al. 2012). This is understandable as a more severe autism diagnosis likely translates into more behaviour challenges and less communication and interaction skills. Challenging behaviour coupled with limited communication skills would result in fewer opportunities for interaction, schooling, and recreation, the very areas that determines a HRQOL score.

In addition to autism severity, behavior problems also negatively affected HRQOL (Kulthau et al 2010). Again this is most likely due to the behavior difficulties interrupting social and physical activities, thus reducing the HRQOL. After reviewing the factors associated with QoL from 16 studies involving more than 3000 participants, Chiang \& Wineman (2014) concluded that there is a critical need to work on improving behavior problems in individuals with ASD in order to improve their QoL.

Kulthau et al (2010) also found that social communication impairment played a role in in determining the HRQOL of children with autism. Social communication impairment refers to an inability to relate to others and interact appropriately in social situation.

Adaptive behavior affects a big part of a person's life and naturally affects their quality of life. Tilford et al (2012) noted that children who had better adaptive behaviour also had better HRQOL.

Two studies (Kose et al., 2013; Sikora et al., 2012) reported that having comorbid psychiatric conditions was negatively associated with QoL of children with ASD.

An interesting finding about HRQOL in adults with autism is that leisure activities affected their HRQOL. Billstedt et al., (2011) and Garcia-Villamisar \& Dattilo, (2010) found that for adults with ASD, participating in leisure activities resulted in higher QoL. Among children with neurodevelopmental disabilities, participating in leisure activities helped to improve their QoL (Dahanoliel, N., Shikako-thomas, K., \& Majnemer, A. 2012). Leisure activities were not investigated as a contributing factor for HRQOL among children with autism, but based on the findings above it could be an important contributing factor. Although rarely discussed in the literature about autism, leisure activities does have its place and helps to improve the HRQOL.

\section{An Intervention Program to Improve the HRQOL among children with autism.}

Based on the factors that affect the HRQOL among children with autism, an intervention program that aims to improve the HRQOL should work on the areas that have an impact on the HRQOL of these children. Since autism severity negatively affects the HRQOL, the intervention program should target core autism symptoms in order to reduce the autism severity. This will include speech, language, communication, and behaviour skills.

As adaptive skills influence HRQOL, the intervention program should specifically target adaptive skills as well. As for comorbid psychiatric disorders, families need to be referred to the relevant specialists to treat the psychiatric disorders in addition to the autism symptoms.

Social communication is another important area as it is a core deficit in children with autism, poor social communication negatively affects HRQOL, and limited social communication often is the cause for limitations in life participation and activities that has the potential to improve the quality of life of 
children with autism. The intervention program should target social communication as it has the greatest potential for improvement in HRQOL.

Parent training, especially in the areas of behavior management and improving communication skills are known to improve these skills in children with autism, in addition to reducing stress among parents (Singh, Lancioni, Winton, Karazsia, Myers, Latham, and Singh, 2014). Parent training is one of the many treatment modes available for children with autism. It is an extension of family centred care, (FCC) has been linked with improved parent and child outcomes (Hodgetts, Nicholas, Zwaigenbaum, and McConnell, 2013.) Parent training has been used to increase parents' knowledge and skills in behavior management (Cordisco, Strain, \& Depew, 1988), communication skills (Charlop-Christy \& Carpenter, 2000), and social skills (Solomon, Necheles, Ferch, \& Bruckman, 2007).

The National Research Council (2001) recommends that parent training should be an essential component in a successful autism intervention program. This is based on a systematic review of the literature, which found that early intervention, intensive programming, and inclusion of family members in intervention resulted in effective treatment. Hence, an ideal intervention program should merge the areas that affect HRQOL as the treatment content and the best practice guidelines and benefits of parent training as the mode of deliver, resulting in a parent mediated intervention targeting areas that improve HRQOL.

\section{Conclusion}

A well planned intervention with a clear outcome measure or objective of improving the HRQOL will be of great benefit to parents and children with autism spectrum disorder. The intervention should be carefully designed to include the areas that affect HRQOL such as social communication skills and behaviour management. The mode of intervention would be best delivered via a parent mediated intervention as this will encompass best practice guidelines of an intervention being family centred and including the parents in the intervention process.

\section{References}

American Psychiatric Association. (2013). Diagnostic and statistical manual of mental disorders (DSM-5®). American Psychiatric Pub.

Blumberg, S. J., Bramlett, M. D., Kogan, M. D., Schieve, L. A., Jones, J. R., \& Lu, M. C. (2013). Changes in prevalence of parent-reported autism spectrum disorder in school-aged US children: 2007 to 2011-2012. National health statistics reports, 65(20), 1-7.

Calder, L., Hill, V., \& Pellicano, E. (2013). 'Sometimes I want to play by myself': Understanding what friendship means to children with autism in mainstream primary schools. Autism, 17(3), 296316.

Charlop-Christy, M. H., \& Carpenter, M. H. (2000). Modified incidental teaching sessions a procedure for parents to increase spontaneous speech in their children with autism. Journal of Positive Behavior Interventions, 2(2), 98-112.

Chiang, H. M., \& Wineman, I. (2014). Factors associated with quality of life in individuals with autism spectrum disorders: A review of literature. Research in autism spectrum disorders, 8(8), 974986.

Cordisco, L. K., Strain, P. S., \& Depew, N. (1988). Assessment for generalization of parenting skills in home settings. Research and Practice for Persons with Severe Disabilities, 13(3), 202-210.

Dahan-Oliel, N., Shikako-Thomas, K., \& Majnemer, A. (2012). Quality of life and leisure participation in children with neurodevelopmental disabilities: a thematic analysis of the literature. Quality of Life Research, 21(3), 427-439.

Developmental, D. M. N. S. Y., \& 2010 Principal Investigators. (2014). Prevalence of autism spectrum disorder among children aged 8 years-autism and developmental disabilities monitoring network, 11 sites, United States, 2010. Morbidity and mortality weekly report. Surveillance summaries (Washington, DC: 2002), 63(2), 1. 
Family Health Division. Ministry of Health Malaysia. Prosiding Mesyuarat Membincangkan Hasil Kajian Saringan dan Pengendalian Masalah Autisme. Kuala Lumpur 2006.

García - Villamisar, D. A., \& Dattilo, J. (2010). Effects of a leisure programme on quality of life and stress of individuals with ASD. Journal of Intellectual Disability Research, 54(7), 611-619.

Granpeesheh, D., Tarbox, J., Najdowski, A. C., \& Kornack, J. (2014). Evidence-based treatment for children with autism: the CARD model. Elsevier.

Hodgetts, S., Nicholas, D., Zwaigenbaum, L., \& McConnell, D. (2013). Parents' and professionals' perceptions of family-centered care for children with autism spectrum disorder across service sectors. Social Science \& Medicine, 96, 138-146.

Jensen, V. K., \& Spannagel, S. C. (2011). The spectrum of autism spectrum disorder: A spectrum of needs, services, and challenges. Journal of Contemporary Psychotherapy, 41(1), 1-9. doi:http://dx.doi.org/10.1007/s10879-010-9161-1

Kose, S., Erermis, S., Ozturk, O., Ozbaran, B., Demiral, N., Bildik, T., et al. (2013). Health related quality of life in children with autism spectrum disorders: The clinical and demographic related factors in Turkey. Disorders Research in Autism Spectrum, 7, 213-220.

Kuhlthau, K., Kovacs, E., Hall, T., Clemmons, T., Orlich, F., Delahaye, J., \& Sikora, D. (2013). Health-related quality of life for children with ASD: Associations with behavioral characteristics. Research in Autism Spectrum Disorders, 7(9), 1035-1042.

Kuhlthau, K., Orlich, F., Hall, T. A., Sikora, D., Kovacs, E. A., Delahaye, J., \& Clemons, T. E. (2010). Health-related quality of life in children with autism spectrum disorders: Results from the autism treatment network. Journal of autism and developmental disorders, 40(6), 721-729.

Lai, M., Lombardo, M. V., \& Baron-Cohen, S. (2014). Autism. The Lancet, 383(9920), 896-910

Laugeson, E. A., Gantman, A., Kapp, S. K., Orenski, K., \& Ellingsen, R. (2015). A Randomized Controlled Trial to Improve Social Skills in Young Adults with Autism Spectrum Disorder: The UCLA PEERS ${ }^{\circledR}$ Program.Journal of autism and developmental disorders, 45(12), 3978-3989.

Lombardo, M. V., Pierce, K., Eyler, L. T., Barnes, C. C., Ahrens-Barbeau, C., Solso, S., ... \& Courchesne, E. (2015). Different functional neural substrates for good and poor language outcome in autism. Neuron, 86(2), 567-577.

Magiati, I., Tay, X. W., \& Howlin, P. (2014). Cognitive, language, social and behavioural outcomes in adults with autism spectrum disorders: A systematic review of longitudinal follow-up studies in adulthood. Clinical Psychology Review, 34(1), 73-86.

Montes, G., \& Halterman, J. S. (2007). Psychological functioning and coping among mothers of children with autism: A population-based study. Pediatrics, 119(5), e1040-e1046.

National Research Council (2001) Educating Children with Autism. Committee on Educational Interventions for Children with Autism. Catherine Lord and James P.McGee, eds. Division of Behavioral and Social Sciences and Education. Washington, DC: National Academy Press.

Olsson, N. C., Tammimies, K., \& Bölte, S. (2015). Manualized social skills group training for children and adolescents with higher functioning autism spectrum disorder: protocol of a naturalistic multicenter, randomized controlled trial. Translational Developmental Psychiatry, 3.

Sikora, D. M., Vora, P., Coury, D. L., \& Rosenberg, D. (2012). Attention-deficit/hyperactivity disorder symptoms, adaptive functioning, and quality of life in children with autism spectrum disorder. Pediatrics, 130(Supplement 2), S91-S97.

Singh, N. N., Lancioni, G. E., Winton, A. S., Karazsia, B. T., Myers, R. E., Latham, L. L., \& Singh, J. (2014). Mindfulness-based positive behavior support (MBPBS) for mothers of adolescents with autism spectrum disorder: Effects on adolescents' behavior and parental stress. Mindfulness, 5(6), 646-657.

Solomon, R., Necheles, J., Ferch, C., \& Bruckman, D. (2007). Pilot study of a parent training program for young children with autism The PLAY Project Home Consultation program. Autism, 11(3), 205-224.

Tilford, J. M., Payakachat, N., Kovacs, E., Pyne, J. M., Brouwer, W., Nick, T. G., ... \& Kuhlthau, K. A. (2012). Preference-based health-related quality-of-life outcomes in children with autism spectrum disorders. Pharmacoeconomics, 30(8), 661-679.

Tung, L. C., Huang, C. Y., Tseng, M. H., Yen, H. C., Tsai, Y. P., Lin, Y. C., \& Chen, K. L. (2014). Correlates of health-related quality of life and the perception of its importance in caregivers of children with autism. Research in Autism Spectrum Disorders, 8(9), 1235-1242. 
Volkmar, F. R., Paul, R., Rogers, S. J., \& Pelphrey, K. A. (Eds.). (2014). Handbook of Autism and Pervasive Developmental Disorders, Diagnosis, Development, and Brain Mechanisms (Vol. 1). John Wiley \& Sons. 